\title{
Endoscopic ultrasound-guided recanalization of a complete esophageal stricture
}

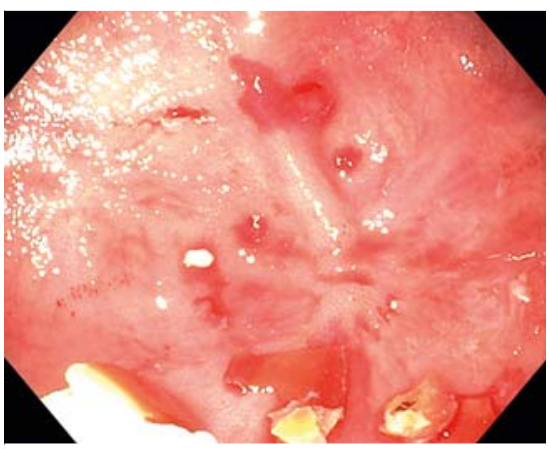

- Fig. 1 Endoscopic view of the complete esophageal stricture.

Complete esophageal strictures are rare and pose technical challenges in management. We present a case of a 34-year-old man with a long-standing history of uncontrolled gastroesophageal reflux disease (GERD) who was referred for management of a complete esophageal stricture. Prior to his presentation, a gastrostomy tube was placed surgically owing to severe malnutrition.

Esophagogastroduodenoscopy revealed a complete esophageal stricture at 35 $\mathrm{cm}$ from the incisors without a clear luminal opening ( $>$ Fig. 1 ). Contrast was instilled and fluoroscopically confirmed the endoscopic findings of a complete esophageal stricture. The decision was made to attempt endoscopic ultrasound (EUS)-guided placement of a lumen-apposing metal stent (LAMS). Initial endosonographic evaluation did not reveal a clear window to target a safe recanalization attempt ( $>$ Fig. 2 ). The gastrostomy tube was used to instill copious amount of sterile water to distend the stomach allowing a target for LAMS placement under fluoroscopic and endosonographic guidance ( Fig.3). Once a safe window was achieved, a 196 needle puncture was performed and a 0.0125-inch guidewire was passed into the gastric lumen ( $\mathbf{F i g}$.4). The LAMS was then deployed over the guidewire using electrocautery, and the fluid instilled into the stomach was seen passing through the

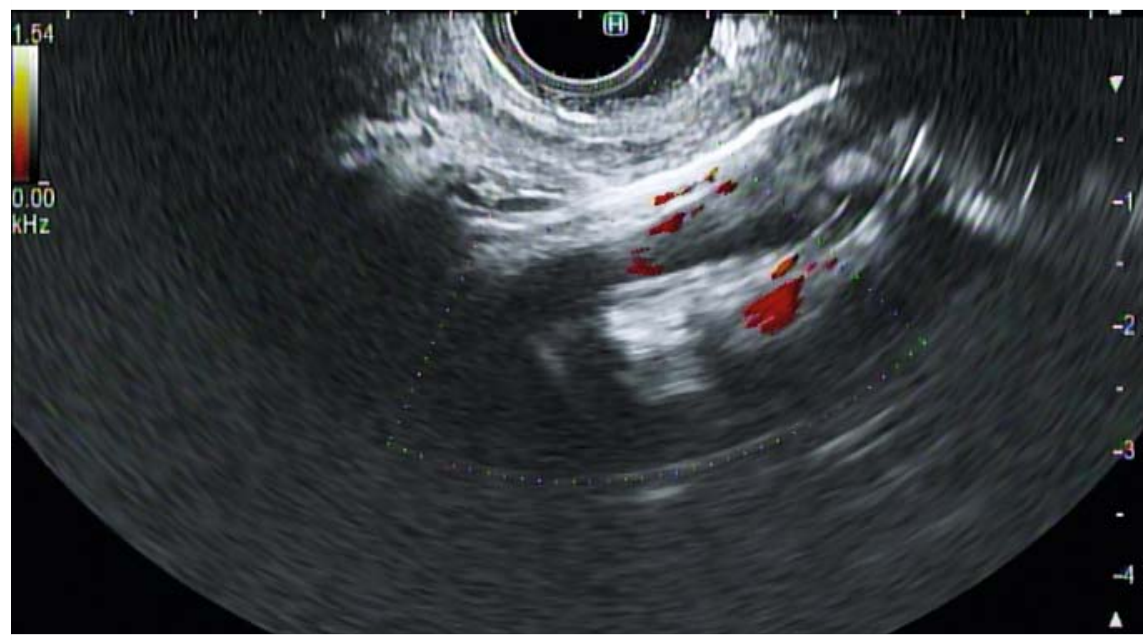

- Fig. 2 Endosonographic view prior to water irrigation through the gastrostomy tube, revealing no clear window to target lumen-apposing metal stent placement.

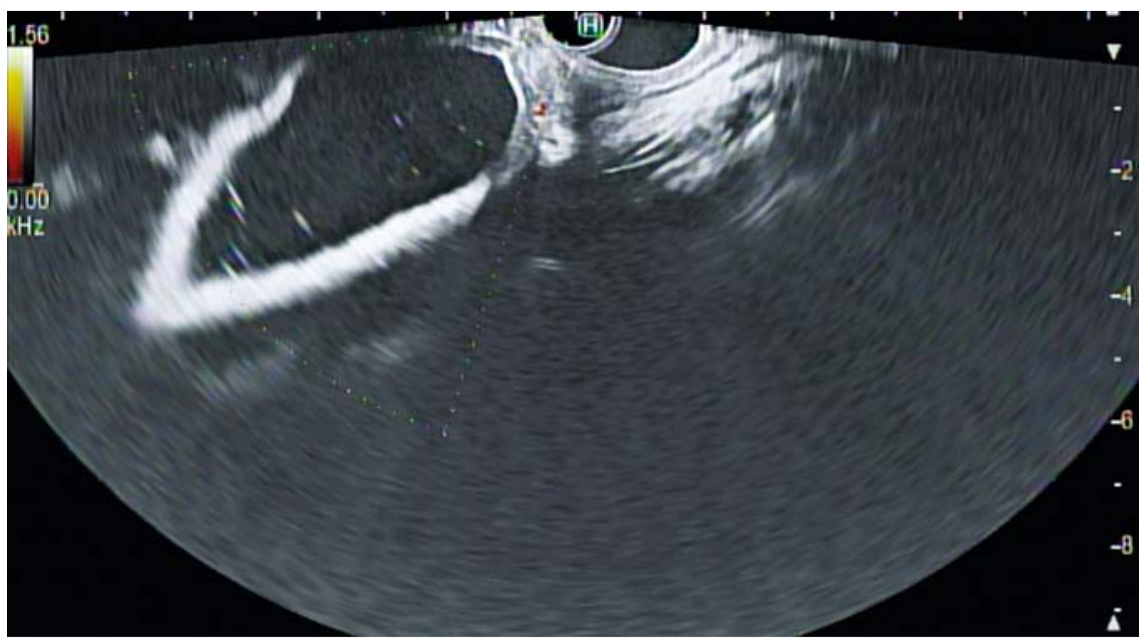

- Fig.3 Endosonographic view after water irrigation through the gastrostomy tube.

stent ( $\triangleright$ Fig. 5). The LAMS was then dilated using the through-the-scope esophageal balloon dilator up to $10 \mathrm{~mm}$. At 4 weeks post-procedure, the patient is tolerating a soft diet and has gained 16 pounds.

Gastrostomies have been utilized to recanalize complete esophageal strictures using an antegrade and retrograde endoscopic approach for proximal strictures [1, 2]. In our case, the gastrostomy tube was used to create a pocket of fluid in the stomach to allow a target for LAMS deployment in the distal esophagus ( Video 1).

EUS-guided recanalization using a LAMS is an efficacious and safe option for patients with complete esophageal strictures. These interventions may prevent the need for more invasive surgical interventions.

Endoscopy_UCTN_Code_TTT_1AS_2AB 


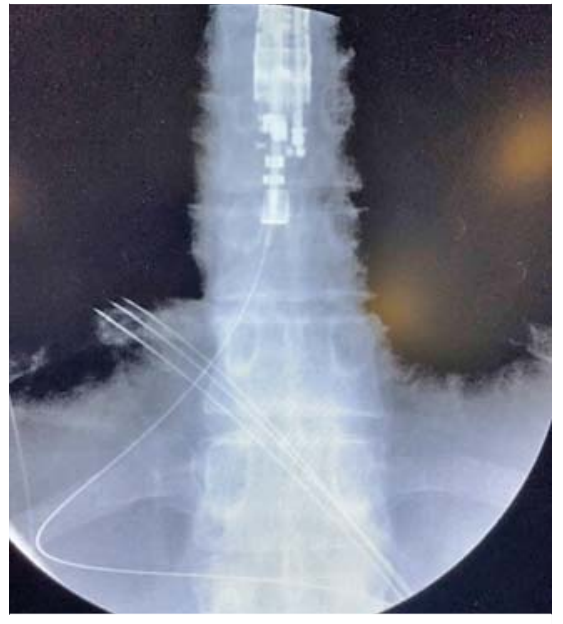

> Fig. 4 Fluoroscopic view after 19G needle puncture and wire advancement into the gastric lumen.

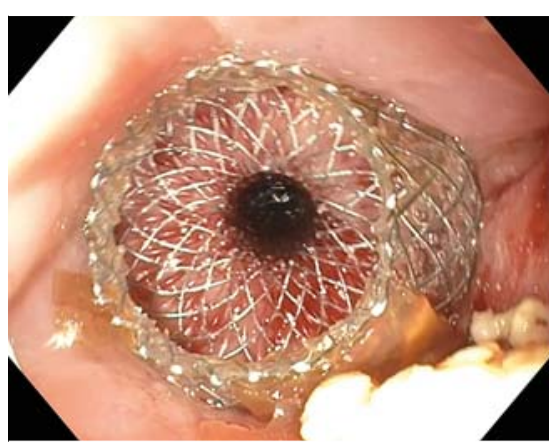

> Fig. 5 Recanalized esophageal lumen after deployment of lumen-apposing metal stent.

\section{Competing interests}

The authors declare that they have no conflict of interest.

The authors

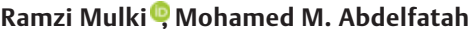

University of Alabama at Birmingham, UAB

Department of Medicine, Division of

Gastroenterology and Hepatology, Birmingham,

Alabama, USA

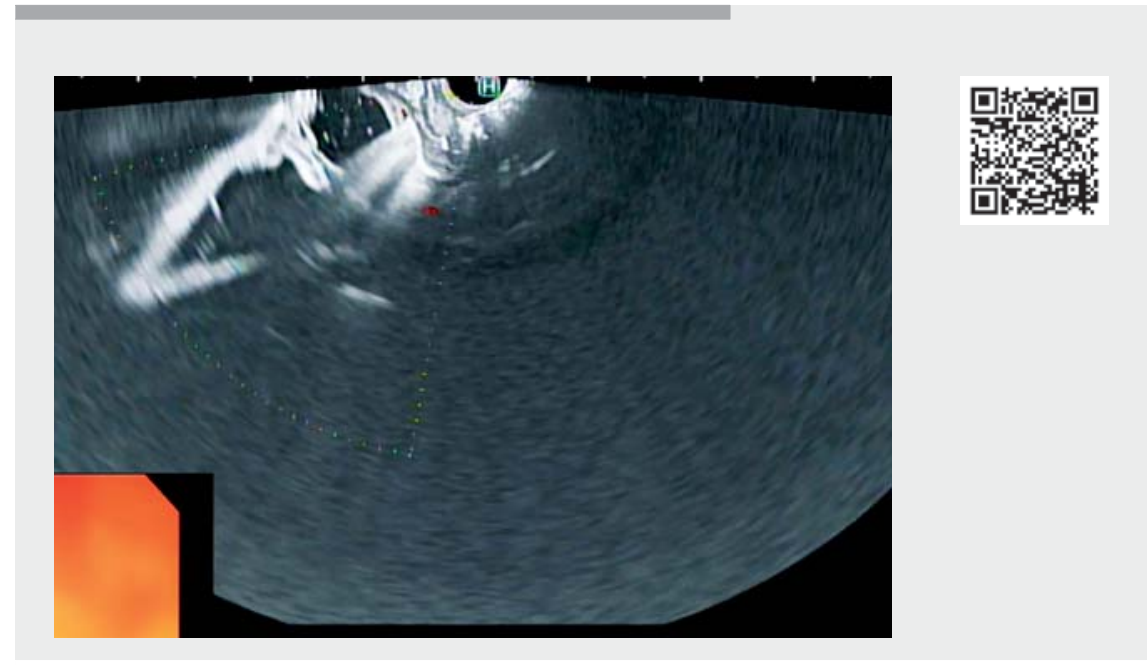

$\checkmark$ Video 1 Endoscopic ultrasound-guided recanalization of a complete esophageal stricture using a lumen-apposing metal stent.

Corresponding author

\section{Mohamed M. Abdelfatah, MD}

University of Alabama at Birmingham,

Division of Gastroenterology and

Hepatology, 1720 University Blvd.,

Birmingham, AL 35294, USA

dr.mohamed.magdy@hotmail.com

\section{References}

[1] Kim M, Kats D, Kahaleh M. Kissing scopes: treatment of complete esophageal obstruction using combined antegrade/retrograde approach. Endoscopy 2021; 53: E106-E107

[2] Schembre D, Dever JB, Glenn M et al. Esophageal reconstitution by simultaneous antegrade/retrograde endoscopy: re-establishing patency of the completely obstructed esophagus. Endoscopy 2011; 43: 434437

\section{Bibliography}

Endoscopy 2022; 54: E156-E157

DOI 10.1055/a-1418-7609

ISSN 0013-726X

published online 16.4.2021

(c) 2021. Thieme. All rights reserved.

Georg Thieme Verlag KG, Rüdigerstraße 14 70469 Stuttgart, Germany

\section{ENDOSCOPY E-VIDEOS \\ https:/|eref.thieme.de/e-videos}

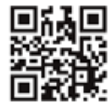

Endoscopy E-Videos is an open access online section, reporting on interesting cases and new techniques in gastroenterological endoscopy. All papers include a high quality video and all contributions are freely accessible online. Processing charges apply (currently EUR 375), discounts and wavers acc. to HINARI are available.

This section has its own submission website at

https://mc.manuscriptcentral.com/e-videos 